\title{
Overcoming the limitations of subxiphoid uniportal video-assisted thoracoscopic surgery and future concerns
}

\author{
Amr Abdellateef ${ }^{1,2}$, Lei Jiang ${ }^{2}$ \\ ${ }^{1}$ Department of Cardiothoracic Surgery, Mansoura University Hospital, Mansoura School of Medicine, Mansoura University, Mansoura, Egypt; \\ ${ }^{2}$ Department of Thoracic Surgery, Shanghai Pulmonary Hospital, Tongji University School of Medicine, Shanghai 200433, China \\ Correspondence to: Lei Jiang. Department of Thoracic Surgery, Shanghai Pulmonary Hospital, Tongji University School of Medicine, Shanghai \\ 200433, China. Email: jiangleiem@aliyun.com; Amr Abdellateef. Department of Cardiothoracic Surgery, Mansoura University Hospital, Mansoura \\ School of Medicine, Mansoura University, Mansoura 35111, Egypt; Department of Thoracic Surgery, Shanghai Pulmonary Hospital, Tongji \\ University School of Medicine, Shanghai 200433, China. Email: amr_abdellateef@mans.edu.eg. \\ Response to: Bertolaccini L, Petrella F, Spaggiari L. Climbing the slope of the learning curve in the subxiphoid uniportal video-assisted thoracic \\ surgery approach. Shanghai Chest 2019;3:33.
}

Received: 08 August 2019; Accepted: 26 August 2019; Published: 12 September 2019.

doi: $10.21037 /$ shc.2019.09.01

View this article at: http://dx.doi.org/10.21037/shc.2019.09.01

There is no doubt that video-assisted thoracoscopic surgery (VATS) has been a safe and effective alternative to open surgery with the same or even superior results regarding safety and oncological efficacy in addition to the advantage of being a minimally invasive approach (1). Reduction of ports number up to only one port in a trial to minimize tissue trauma and consequently the postoperative pain has been developed over the past few years either through the intercostal or subxiphoid VATS (SVATS) approaches $(2,3)$.

From that point, we extremely appreciate the editorial commentary published by Bertolaccini et al. (4) on the published paper of Abdellateef et al. (5). Primarily, trials to avoid intercostal incision through the subxiphoid approach was to further lessen postoperative pain. Then, the literature started gradually to report other advantages for subxiphoid approach like faster postoperative mobilization with lesser incidence of chest infection and thromboembolism (6). In addition, SVATS has been considered as an efficient approach to mediastinal masses and thymectomy with good visualization of both phrenic nerves bilaterally, faster and ideal approach for bilateral lesions or concomitant pulmonary and mediastinal approach through single incision without need to intraoperative change of patient's position (7). Furthermore, it offers easier angle for passage of dissectors and staplers around blood vessels and bronchus during major pulmonary resection (5).
As any newly developed technique, SVATS has had some limitations like the need for dedicated training and relatively stepwise learning curve due to different angle of instrumentation and axis of visualization rather than the familiar intercostal view and instrumentation. However, we can have a look on the rapidly growing literature delivering the different implications of subxiphoid approach starting from simple bullectomy passing by more complex procedures as thymectomy, lobectomy, segmentectomy and other complex bilateral pulmonary resections (5-8). That may indicate that the matter of accommodation on the different view and way of instrumentation has been just time factor and has been overcome with the progressing learning curve.

Risk of arrhythmia specially on left sided operations, need for wide subcostal angle and more difficult approach to posterior thoracic structures arose the necessity of patient and lesion selection criteria like avoidance of obese patients, patients with cardiac problems and posteriorly located lesions. But, the increasing number of adopting surgeons for SVATS increased the interest to develop specially designed long curved instruments which facilitated the technique, lessened the compression on the heart and eased the reach to posterior thoracic structures. Also, by the growing experience, many tips and tricks have arisen and published to guide surgeons to safer and easier subxiphoid technique (9).

In conclusion, difficulty and limitations of SVATS 
are being overcome by the growing surgeons' expertise. Concerns regarding long term follow up, proving the oncological efficacy and actual effect on quality of life should be the goals of future research through multicenter and randomized studies.

\section{Acknowledgments}

Funding: None.

\section{Footnote}

Provenance and Peer Review: This article was commissioned and reviewed by the Section Editor Fabrizio Minervini (Department of Thoracic Surgery, Luzerner Kantonsspital, Lucerne, Switzerland).

Conflicts of Interest: Both authors have completed the ICMJE uniform disclosure form (available at http://dx.doi. org/10.21037/shc.2019.09.01). The authors have no conflicts of interest to declare.

Ethical Statement: The authors are accountable for all aspects of the work in ensuring that questions related to the accuracy or integrity of any part of the work are appropriately investigated and resolved.

Open Access Statement: This is an Open Access article distributed in accordance with the Creative Commons Attribution-NonCommercial-NoDerivs 4.0 International License (CC BY-NC-ND 4.0), which permits the noncommercial replication and distribution of the article with the strict proviso that no changes or edits are made and the original work is properly cited (including links to both the formal publication through the relevant DOI and the license). See: https://creativecommons.org/licenses/by-nc-nd/4.0/.

doi: 10.21037/shc.2019.09.01

Cite this article as: Abdellateef A, Jiang L. Overcoming the limitations of subxiphoid uniportal video-assisted thoracoscopic surgery and future concerns. Shanghai Chest 2019;3:57.

\section{References}

1. Zhang Z, Zhang Y, Feng H, et al. Is video-assisted thoracic surgery lobectomy better than thoracotomy for early-stage non-small-cell lung cancer? A systematic review and metaanalysis. Eur J Cardiothorac Surg 2013;44:407-14.

2. Harris CG, James RS, Tian DH, et al. Systematic review and meta-analysis of uniportal versus multiportal videoassisted thoracoscopic lobectomy for lung cancer. Ann Cardiothorac Surg 2016;5:76-84.

3. Song N, Zhao DP, Jiang L, et al. Subxiphoid uniportal video-assisted thoracoscopic surgery (VATS) for lobectomy: a report of 105 cases. J Thorac Dis 2016;8:S251-7.

4. Bertolaccini L, Petrella F, Spaggiari L. Climbing the slope of the learning curve in the subxiphoid uniportal video-assisted thoracic surgery approach. Shanghai Chest 2019;3:33.

5. Abdellateef A, Yang C, Chen J, et al. Subxiphoid uniportal video assisted thoracoscopic surgery lobectomy, evolution of the technique and progress of learning curve. Shanghai Chest 2018;2:88.

6. Ali J, Haiyang F, Aresu G, et al. Uniportal subxiphoid videoassisted thoracoscopic anatomical segmentectomy: technique and results. Ann Thorac Surg 2018;106:1519-24.

7. Abu-Akar F, Gonzalez-Rivas D, Yang C, et al. Subxiphoid uniportal VATS for thymic and combined mediastinal and pulmonary resections - a two-year experience. Semin Thorac Cardiovasc Surg 2019. [Epub ahead of print].

8. Chen L, Liu F, Wang B, et al. Subxiphoid vs transthoracic approach thoracoscopic surgery for spontaneous pneumothorax: a propensity score-matched analysis. BMC Surg 2019;19:46.

9. Abdellateef A, Ali JM, Jiang G, et al. Tips and tricks for success in subxiphoid video-assisted thoracic surgery. J Thorac Dis 2019;11:292-301. 